\title{
Cómo se hace un autor. Acerca del contacto cultural entre ciudades (Córdoba / Buenos Aires, 1880-1930)
}

\section{RMA}

Antropología Social
Ana Clarisa Agüero

Becaria de Postgrado CONICET/CIFFyH/Museo de Antropología Facultad de Filosofía y Humanidades, Universidad Nacional de Córdoba anaclarisaa@yahoo.es

Resumen

¿Cómo hacer una historia de la edición en ausencia de su prehistoria descriptiva, serial o cualitativa? La pregunta caracteriza el punto de partida de toda indagación cifrada en el antiguo mundo de folletos, libros y revistas cordobeses; esfuerzo tensado entre magros antecedentes locales y sofisticados estímulos externos. Así las cosas, parece no haber otro modo de proceder que mediante la elaboración simultánea de grandes mapas de la evolución y los sucesivos estados de ese mundo y acotados avances intensivos sobre casos especialmente representativos o significativos. Un avance de ese tipo ha comenzando a despejar las instancias y modalidades de realización de lo impreso en el giro de siglo, a la vez que ha puesto de relieve su carácter altamente heterónomo. En efecto, desde la escritura de textos hasta su exhibición en las vidrieras bajo la forma de libro, todo lo que de editorial pueda señalarse en Córdoba es tanto local cuanto porteño o europeo y debe, consecuentemente, ser pensado en una escala adecuada a la territorialidad de cada contacto cultural. La fábrica del autor, uno de los fenómenos que la consideración relacional vuelve notable y tema del presente artículo, permite apreciar de manera muy clara la postulada heteronomía.

Palabras clave: edición - fábrica del autor - contacto cultural - ciudades - nación

How an author becomes. About the cultural contact between cities (Córdoba / Buenos Aires, 1880-1930)

\begin{abstract}
How does one build a history of publishing in the absence of a descriptive, serial or qualitative prehistory? The question characterizes the starting point of all inquiry focusing the ancient world of cordobean booklet, books and magazines; an effort strained between meager local precedents and sophisticated external stimuli. Been that the case, there is no other way than simultaneous elaboration of large maps of the evolution and successive states of that world, and bounded and intensive advances on specially representative or significant cases. Such an advance has begun to clear the instances and modalities of realization of the printed thing in the turn of the century, while throwing a light its heteronomous character. In fact, from the writing stage until the moment of the exhibition in the shopwindows in the form of book, any editorial fact that could be pointed out regarding Córdoba is as much local as porteño or European and should, consequently, be considered on scale adequate to the territoriality of each cultural contact. The making of the author, phenomenon highlighted by the relational consideration and topic of the present article, allows us to appreciate in a very clear way the postulated heteronomy.
\end{abstract}

Keywords: publishing - the making of the author - cultural contact - cities - nation

«¿Quién habla? ¿Quién escribe? Nos falta aún una sociología de la palabra.» Roland Barthes, «'Écrivains” y 'écrivants'», 1960

«Quizás es tiempo de estudiar los discursos ya no sólo en su valor expresivo o en sus transformaciones formales, sino en las modalidades de su existencia...» Michel Foucault, ¿Qué es un autor?, Paris, 1969

1. ¿Cómo hacer una historia de la edición en ausencia de su prehistoria descriptiva, serial o cualitativa? La pregunta caracteriza el punto de partida de toda indagación cifrada en el antiguo mundo de folletos, libros y revistas cordobeses; esfuerzo, por lo demás, tensado entre magros antecedentes locales y sofisticados estímulos externos (de Martin- Febvre a Darnton). ${ }^{1}$

Así las cosas, parece no haber otro modo de proceder que mediante la elaboración simultánea de grandes mapas de la evolución y los sucesivos estados de ese mundo y acotados avances intensivos sobre casos especialmente representativos o significativos. ${ }^{2}$ Lo primero, tendiente a restituir el universo de ámbitos, agentes y productos involucrados; lo segundo, a fines de comprender de 
manera más cabal la naturaleza sociológica, técnica o simbólica de cada uno de ellos. Un avance de ese tipo, a la vez cartográfico e intensivo, ha comenzando a despejar las instancias y modalidades de realización de lo impreso en el giro de siglo, a la vez que ha puesto de relieve su carácter altamente heterónomo. ${ }^{3}$ En efecto, desde la escritura de textos hasta su exhibición en las vidrieras bajo la forma de libro, todo lo que de editorial pueda señalarse en Córdoba es tanto local cuanto porteño o europeo y debe, consecuentemente, ser pensado a una escala que permita relevar las confluencias, superposiciones y mixturas propias de todo contacto cultural. La fábrica del autor, uno de los fenómenos que la consideración relacional vuelve notable y tema del presente artículo, permite apreciar de manera muy clara la postulada heteronomía.

2. En 1900, las treinta imprentas cordobesas que habían sido activas, algunas nacido y sucumbido, desde el ochenta, podían jactarse de haber vuelto libro o folleto textos históricos de Juan M. Olmos, literarios de José María Vélez y jurídicos de Cipriano Soria; compacto grupo al que hoy une, ante todo, el más cruento anonimato. Dado que ese oscurecimiento autoral convive, a veces, con reconocimientos políticos o académicos, parece haber en el devalúo más que un específico tamiz de calidad o un deliberado trabajo de ocultamiento. A nuestro juicio, una buena parte de él reconduce a coordenadas más amplias tanto territorialmente (la perspectiva de convertirse en autor no deriva sólo de la suerte corrida en algún ámbito local) cuanto materialmente (ella tampoco se explica por la mera elaboración de un determinado canon disciplinar). En efecto, lo que intentamos compulsar es la idea de que la operación social por la cual se adjudica a un sujeto la condición de autor (ligada a la elaboración de un nombre, la atribución de una obra y el despliegue de un mercado) es, en el giro de siglo argentino, una operación decididamente nacional; esto es, una operación que tiene lugar en una geografía dilatada pero, también, sensiblemente jerarquizada y, por tanto, dominada por el ámbito al cual se reconocen las cualidades del centro. ${ }^{4}$ Dicho en otros términos, autores son aquellos que logran persistir en la llegada de su nombre y sus textos a Buenos Aires y, especialmente, quienes logran convertirlos en impresos y difundirlos desde esa ciudad. Si, como sugerimos, la cuestión se dirime en el centro, la consideración de la suerte corrida por ciertas figuras de provincias parece un mirador doblemente adecuado ya que, más allá del mero juego de inclusiones y exclusiones, permite advertir una geografía móvil de aproximaciones, merodeos, instalaciones y vueltas al pago que afecta tanto al nombre cuanto al texto, el libro o el sujeto.

Es sencillo constatar que no todos los pretendientes llegaron a ser reconocidos como autores de historia, derecho, ciencia o literatura. $Y$ si esa constatación no es excepcional resalta, al menos, la conveniencia de pensar en términos de fábrica del autor; es decir, de una elaboración compleja, mediada por instituciones como las academias, por empresas grandes o pequeñas, por un público en formación y, en alguno que otro caso, por el tipo de cualidades individuales que es habitual presumir en el origen del canon. ${ }^{5}$ Puesto que, a la vez, nada hay menos natural que el canon, todo esfuerzo por mostrar esa fábrica debe privilegiar, en la senda marcada por Pierre Bourdieu, aquellos elementos ocluidos por las variantes de la ideología del genio, que son los que en buen grado hicieron de Ramón J. Cárcano, Pablo J. Cabrera, Juan M. Garro, Leopoldo Lugones, Martín Gil o Raúl Orgaz verdaderos autores. ${ }^{6}$ Para esto, nos parece, es preciso avanzar en el cotejo de diversas series (ediciones y lugares de edición, prólogos, comentarios bibliográficos, datos centrales de trayectoria), porque en ese cotejo la autoría se muestra en toda su laboriosidad, surgiendo o siendo denegada entre Córdoba y Buenos Aires. Aunque, en términos generales, la importancia de la mediación porteña puede defenderse respecto de todos los nombres citados, consideraremos apretadamente dos casos, el de Juan M. Garro, universitario de Córdoba de origen puntano, y el de Martín Gil, universitario de Buenos Aires de origen cordobés y larga actuación en ambas ciudades.

3. El nacimiento autoral de Juan M. Garro (18471927) es, en buena medida, obra de la Nueva Revista de Buenos Aires. No se trata sólo de que éste hubiera ido volcando allí los avances de su Bosquejo Histórico de la Universidad de Córdoba sino de que, conforme el propio programa de la revista, esos anticipos preparaban la aparición del libro. ${ }^{7}$ De este modo Garro, que acababa de concluir su diputación nacional por San Luis, fue adelantando allí partes de su Bosquejo, a la vez que encontró en la «Bibliografía» de la Revista el más entusiasta comentador cuando ellas se convirtieron en libro. ${ }^{8}$ Pocas cosas muestran mejor la fábrica del autor que la insistencia de la Nueva Revista en los méritos, actuales y anteriores, que inclinaban $-y$ comprometían- a Garro a serlo:

«El doctor Garro no es un desconocido: ha llegado precedido del aprecio de los que habían conocido su velor [sic], en laboriosas discusiones en la cámara de Diputados de la Nación [...] Cuando terminó sus tareas parlamentarias [...] ha escrito la historia interesante de la más antigua de las Universidades en el territorio que hoy forma la República Argentina. Ha indagado en las fuentes originales, en los archivos y entre los documentos de aquella Universidad famosa, y ahora presenta el fruto sazonado de sus vigilias. La NUEVA REVISTA saluda a su autor como a un viejo conocido, y recibe este nuevo 
libro como la promesa de futuros trabajos - para aumentar el caudal literario nacional.» ${ }^{9}$

Es lícito presumir que el ejercicio de su diputación permitió a Garro consolidar los lazos que lo llevaron a la Nueva Revista; y, en efecto, éste se vuelve nacional porque es político. Pero, además, Garro es católico, y su catolicismo militante, crecientemente politizado, es también un factor principal de nacionalización. ${ }^{10}$ Visto desde esta perspectiva, el Bosquejo se urde conjuntamente al vínculo con Estrada, algo que resuena en la elección de Biedma -que había publicado, al menos, tres «estradas» entre 1877 y 1880- como su impresor. ${ }^{11}$ De este modo, un texto que tematizaba el espacio cordobés, era firmado por un puntano y vuelto libro en prensa porteña. $Y$ puesto que la Nueva Revista se interesaba por la aparición del libro pero también por la del autor (una faceta de sus continuas lamentaciones sobre el estado de la cultura argentina), no debe sorprender que, luego de la salutación, condenara la falta de apoyo de la universidad cordobesa, virtualmente incapaz de acompañar -sostener- la gesta de Garro.

En poco tiempo, el libro - presente en múltiples bibliotecas privadas, como las de Cabrera y Dussaut y en las principales públicassería de consulta ineludible para todo interesado en la historia de Córdoba y su Universidad; pero para que eso ocurriera, también, hubieron de sumarse las objeciones de Abraham Argañaras, franciscano cordobés que llevó a prensa porteña, casi de inmediato, sus Rectificaciones (1883).12 Garro respondió con un breve folleto local que, impreso por el Eco de Córdoba, reforzaba sus créditos católicos. Esa discreta respuesta local, sin embargo, tenía lugar el mismo año en que su nombre sonaba, a escala nacional, en la célebre Asamblea de Católicos Argentinos. ${ }^{13}$

Las vicisitudes del Bosquejo grafican bien el modo en que Garro conduce sus apuestas localnacionales, según un arte combinatorio orientado a compensar, entre Córdoba y Buenos Aires, las altas y bajas de sus créditos políticos, académicos, religiosos e intelectuales. Miembro de la Junta Revolucionaria que expulsó al juarismo, Garro endereza en la Capital la larga inquina políticoacadémica local iniciada con la tesis de Cárcano; catedrático cordobés, abona su futuro decanato en Buenos Aires; candidato a la vicepresidencia por la UCR, se aleja de EI Porvenir pero redobla su presencia política y cultural en Córdoba. ${ }^{14}$ Su constitución autoral es, en este sentido, un capítulo de ese juego regular de apuestas, acumulación y compensación en una amplia geografía: en 1896, Garro biografía a Estrada para la edición de sus Obras Completas, algo que lo consolida genéricamente como autor, a la vez que puntualmente como sucesor en el espacio católico; desde 1899 escribe en la Revista de Derecho, Historia y Letras de Zeballos, actualizando en y desde Buenos Aires sus créditos jurídicos; designado Decano de la Facultad de Derecho de esa ciudad (1906), da vida a su Revista, poniendo de relieve su plus de intelectual-editor. ${ }^{15}$ Producto de esa larga y diversificada sumatoria, hacia 1910 su condición de autor parece ya fuera de discusión: por un lado, satisface el encargo oficial de editar los Escritos y Discursos de Avellaneda, cuya «Noticia biográfica» firma y publica también separadamente; por otro, expresa su autoridad (puesto que todo prólogo implica una transferencia de prestigio) al prologar las Tradiciones puntanas de Juan Gez, quien luego sería su biógrafo. ${ }^{16}$ Cerrando el ciclo, en 1916 Weiss y Preusche imprimía sus Páginas dispersas, obra que otros cordobeses devenidos autores en esos años leerían con tanta atención como el Bosquejo. ${ }^{17}$ Un caso relevante es el de Pablo Cabrera (1924), de cuyas menciones se desprende que, ya en los veinte, el nombre de aquel viejo universitario de Córdoba podía ser invocado como fuente de una autoridad específica, asociado a una obra, y remitido a un público. ${ }^{18}$

4. Consideremos ahora el caso de Martín Gil (1868-1955), periodista cordobés y narrador de ocasión al momento de esta escena:

«Fines del siglo XIX. Salón en Buenos Aires. // ¿Quién era el que narraba? ¿Quién ese hombre nervioso, menudo y vivaz que a todos deleita con su expresión tan sabrosa? Era Martín Gil quien narraba; y a la tertulia toda, entre mundana y literaria, presidida por un gran señor de las letras y de la alta sociedad, le hacía muchísima gracia el donaire del narrador [...] / / Todos reían. Pero Cárcano, además de reír, como buen conocedor del ambiente campestre, reflexionando a fuer de escritor, le dijo un día a su visitante: // -Usted debería escribir estas cosas; escribirlas tal como las cuenta. [...] No vacile. Ensaye. Escriba. Empiece por Noche de perros, y ya verá como gusta. // El doctor Cárcano acertó. Y cuando el nuevo escritor lanzaba desde Córdoba su primer libro - Prosa Rural- le era dado proclamar a aquél en su Carta Prologal la belleza y utilidad de esas páginas [...] Muy pronto vendría 'el triunfo duradero y resonante'. [...] // Fue Brocha Gorda, o sea don Julio L. de Jaimes [...] quien saludó con el debido encomio la aparición de tan simpática obra, en La Nación del 26 de diciembre de $1900 \ldots{ }^{19}$

Los años de la velada son aquellos en que Cárcano escribe para La Biblioteca de Groussac. Desde su nacionalización merced al juarismo, éste ha pasado más de ocho veces por las prensas porteñas sólo con sus artículos, folletos y libros de carácter histórico. Está, por lo demás, en vísperas de ser integrado a la Junta de Historia y Numismática. Él, entonces, empujando a Gil a la 
escritura, estimulando y prologando desde Buenos Aires su primer libro, hecho en Córdoba pero, fundamentalmente, celebrado por La Nación. El «triunfo», dice Capdevila, aunque en rigor se trate del primer escalón en la fábrica del autor, como revela el derrotero de su segundo libro. Modos de ver (1903) llegará a contar cinco ediciones, muy expresivas del creciente prestigio de Gil. Publicado originalmente por La Italia (imprenta de larga vida que, pese a un par de buenos intentos, será siempre dominada por su costado comercial), tendrá en 1913 una segunda impresión local por Rossi, la casa que más claramente intentó entonces construir catálogo en Córdoba. ${ }^{20}$ En 1920 comienzan sus ediciones porteñas: ese año, la Cooperativa de Edición Limitada, en 1923 la Agencia General de Librería y Publicaciones y, presumiblemente en los '40, Anaconda. La seguidilla es indicativa no sólo de la jerarquización del libro en el espacio local -desde el punto de vista de los pretendientes, la edición por Rossi constituye un reconocimiento intelectual y autoral- sino, también, de sus repercusiones en el centro. Indudablemente, ambos fenómenos habían sido preparados o reforzados por cosas que excedían el texto. Por empezar, inmediato a la primer edición, un encendido debate periodístico entre Manuel Pizarro y Martín Gil sobre las razones primeras y últimas; el uno atacando desde el católico Los Principios, el otro atrincherado en La Patria (Capdevila 1960). El nombre suena, como en los ochenta el de Cárcano, esto es, tanto en Córdoba como en Buenos Aires. En segundo término, la aparición local de Agua Mansa, en 1906. En tercero, la incorporación de Gil a La Nación-desde 1907 y durante más de cuarenta años-, factor central de afirmación en un territorio más vasto. ${ }^{21}$ La eficacia de esta escalada se advierte ya en Cosas de arriba (1909), expresivo de su reorientación astronómica, también salido de prensa cordobesa pero prologado ya por Ángel Gallardo. ${ }^{22} \mathrm{EI}$ movimiento al centro -inicialmente, la nacionalización de un nombre ligado a la escritura- describe una acumulación de los créditos por él expedidos: en 1915, Gil se convierte en miembro de la Academia Nacional de Ciencias y, en 1916, de la Junta de Historia y Numismática. En 1917, gran síntoma, ve la luz su última edición cordobesa, Celestes y cósmicas, impresa por Bautista Cubas. Desde esa fecha, además de sus varias reediciones totales o parciales (entre ellas la de la campera Agua Mansa, en 1924, ahora con una carta de Wilde), pasaría por imprenta porteña, al menos, cinco nuevos libros, muchos de tema astronómico. Su desplazamiento físico a la Capital, ligado a sucesivas funciones, hará irreversible este proceso de construcción autoral que la Academia de Letras consagra en 1935. ${ }^{23} \mathrm{Y}$ aunque esa designación provocara la sonrisa agria de Deodoro Roca ante Gil, escritor "perpetuamente salido de su órbita», ya Gleizer había editado Mirar desde arriba (1930) y Alberto Gerchunoff prologaba ese mismo año su Hablando solo (1935). ${ }^{24}$ Y Xul Solar, y Macedonio Fernández, eran ya sus amigos. La trayectoria de
Gil, semejante a unas (Lugones impulsado a $L a$ Nación por un oscuro Carlos Romagosa), y contrastante con otras contemporáneas (los perdidos nombres que introdujeron al tema), inclina a persistir en la idea de que un autor es algo que se hace - 0 no se hace- en contextos nacionales y conforme diversas variables. En esa medida, las propiedades del fenómeno sugieren, en parte, la escala y, en parte, las modalidades de análisis.

5. Hubo, al comienzo, una definición de método, ligada tanto al estado de la cuestión cuanto a las propiedades de los fenómenos de nuestro interés: la investigación avanza, por fuerza, según una combinatoria de grandes cartografías y puntuales abordajes intensivos. Puesto que lo que se postula es la radical heteronomía de todo hecho de edición, se intentó caracterizar la fábrica del autor merced a instrumentos análogos a los requeridos por el análisis de otro tipo de contactos; y puesto que, a la vez, se entiende que el ámbito de aquella fábrica es ante todo nacional, se privilegió el dilatado espacio definido por dos ciudades que han revestido históricamente diversa jerarquía política y cultural. Si crear autor es un trabajo, y ese trabajo se hace en contextos territorialmente amplios, el análisis de su producción debe integrar variables particulares (en este caso, de edición) y otras comunes a toda sociología de la cultura (como la de trayectoria) para intentar reinscribir lugares físicos y sociológicos. El espacio de esa reunión suele ser una suerte de tabla desarrollada que, al permitir el cotejo, ilumina la artificialidad de la aparición del autor y, al desnaturalizarlo, permite pensar en términos de un proceso de acumulación de credenciales múltiples y de variada jerarquía.

Como la exposición resigna casi todo de la investigación, debe consignarse que las hipótesis generales sobre la fábrica del autor derivan de la consideración simultánea de un amplio conjunto de figuras. Esa cartografía intentó ser densificada y especificada mediante el análisis de los casos de Garro y Gil; figuras representativas si se advierte, a grandes trazos, lo ocurrido con otros devenidos autores (los mencionados Cárcano, Cabrera, Orgaz, etc.) pero, especialmente, confrontadas con aquellos que, pese a escribir y publicar, nunca llegarían a serlo.

Córdoba, 15 de julio de 2008

\section{Bibliografía}

Barthes, R. 2003. 'Écrivains' y 'écrivants'. Ensayos críticos, Seix Barral, Buenos Aires.

Bourdieu, P. 2003. Creencia artística y bienes simbólicos. Elementos para una sociología de la cultura, Aurelia Rivera, Córdoba.

Bourdieu, P. 2003. Las condiciones sociales de la circulación de ideas. Intelectuales, política y poder, Eudeba, Buenos Aires. 
Cabrera, P.J. 1924. Imprentas e impresos en nuestro pasado. Revista de la Universidad Nacional de Córdoba, Vols. 10 a 12, Córdoba.

Cabrera, P. J. 1930. La segunda imprenta de la Universidad de Córdoba adquirida por suscripción popular en 1823 bajo el Gobierno del Gral. Juan Bautista Bustos, UNC, Córdoba.

Canter, J. 1940. La imprenta. Ricardo Levene (edit), Historia de la Nacion Argentina (Desde los orígenes hasta la organización definitiva en 1862), Vol. IV, EI Ateneo, Buenos Aires.

Capdevila, A. 1960. Martín Gil. Ciudadano del cielo. Prólogo a la Antología de Martín Gil, Academia Argentina de Letras, Buenos Aires.

Chartier, R. 1996. El orden de los libros. Lectores, autores, bibliotecas en Europa entre los siglos XIV y XVIII, Gedisa, Barcelona.

Delgado, V., F. Espósito 2006. 1920-1937. La emergencia del editor moderno. José Luis De Diego (dir.), Editores y políticas editoriales en Argentina, 1880-2000, FCE-Libraria, Buenos Aires.

De Ugarteche, F. 1929. La imprenta argentina. Sus orígenes y desarrollo, Canals, Buenos Aires.

Eujanian, A. 2000. La cultura: público, autores y editores. Marta Bonaudo (dir.), Liberalismo, estado y orden burgués (1852-1880), Nueva Historia Argentina, T. IV, Sudamericana, Buenos Aires.

Foucault, M. 1985. ¿Qué es un autor?, Universidad Autónoma de Tlaxcala, México.

Furlong, G. 1924. La imprenta jesuítica de Córdoba. Extracto en Pablo J. Cabrera, «Imprentas e impresos en nuestro pasado», Revista de la Universidad Nacional de Córdoba, Vols. 10 a 12, Córdoba.

Martin, H.-J., L. Febvre 2005. La aparición del libro, FCE-Libraria, México.

Merbilhá, M. 2006. 1900-1919. La época de organización del espacio editorial. José Luis De Diego (dir.), Editores y políticas editoriales en Argentina, 1880-2000, FCE-Libraria, Buenos Aires.

Pastormerlo, S. 2006. 1880-1 899. El surgimiento de un mercado editorial. José Luis De Diego (dir.), Editores y políticas editoriales en Argentina, 18802000, FCE-Libraria, Buenos Aires.

Ramos, J. 1989. Desencuentros de la modernidad en América Latina. Literatura y política, FCE, México.
Río, M. 1956 (1910). La imprenta y los periódicos. Córdoba. 1810-1910, reproducido en Córdoba, su fisonomía y su misión. Escritos y discursos, UNC, Córdoba.

Río, M. 1967 (1910). Córdoba, su fisonomía y su misión. Escritos y discursos, UNC, Córdoba.

Roca, D. 1956 (1935). 'Vidas paralelas' Historia ejemplar de la Academia Argentina de Letras. El difícil tiempo nuevo, Lautaro, Buenos Aires.

Rolla Bertello, E. 1991 . «La biblioteca Dussaut: imprenta e impresores cordobeses del siglo XIX». Facultad de Filosofía y Humanidades. Universidad Nacional de Córdoba, Argentina. Biblioteca Central de la FFyH-UNC.

Sorá, G. 2008a. Le livre et l'édition en Argentine. Livres pour tout le monde et modèle hispano-américain. Martin Lyons, Jaques Michon, Jean-Yves Mollier y François Valloton (orgs.), Histoire nationale or histoire internationale du livre et de l'édition. Un débat planétaire / National or international boook and publishing history? A worldwide discusión, Nota Bene éditions, Québec. (en prensa).

Sorá, G. 2008b. Misión de la edición para una cultura en crisis. El Fondo de Cultura Económica y el americanismo en Tierra Firme. Carlos Altamirano (Dir.), Entre cultura y política: historia de los intelectuales en América Latina, Katz, Buenos Aires.

Sparn, E. 1924. Las bibliotecas con 50.000 y más volúmenes y su distribución geográfica sobre la tierra. Revista de la Universidad Nacional de Córdoba, Vols. 1 a 3, Córdoba.

\footnotetext{
1 Llamativamente, nuestros principales antecedentes provienen, en buena medida, de la misma etapa en estudio; algo que les otorga una fisonomía compleja, entre bibliografía imprescindible y documento fundamental. Se trata, mayormente, de historias de la imprenta en el Río de la Plata, tema especialmente significativo para una ciudad que, como Córdoba, reclama haber sido su primer sede en el actual territorio argentino. Al igual que otros relativos, esos textos fueron producidos por polígrafos, historiadores y bibliófilos. Entre ellos, deben mencionarse los trabajos del jesuita Furlong (donde el interés por la imprenta se superpone a la reválida de la orden como su introductora), los del sacerdote secular Pablo J. Cabrera (entre otros, el de 1924) y, ya reposando sobre estos, la monumental obra de De Ugarteche (1929) y los textos de Juan Canter o Torre Revello de las décadas del ' 30 y del ' 40 . Luego de esta fecha, el caudal de este tipo de estudios decrece lo bastante como para que, hasta hoy, no hayamos sabido mucho más de imprentas o bibliotecas cordobesas que lo poco que estas figuras llegaron a decir.Entre las más significativas historias contemporáneas del libro y la edición -en parte, por deslindar literatura y edición y multiplicar las variables históricas y sociológicas- deben señalarse los trabajos de Sorá (2008 a y b), Eujanián (2000) y algunos de los compilados por José Luis de Diego (2006, según nuestro interés, Pastormerlo, Merbilhá y Delgado-Espósito); trabajos que asumen una
} 
perspectiva nacional aunque, dadas la significación editorial de Buenos Aires y la desigual afirmación de un mercado, se cifren mayormente en el espacio pampeano.

${ }^{2}$ En parte, porque reeditar en tierras americanas la colosal empresa serial que en Francia alentó aproximaciones cualitativas de enorme interés (Chartier 1996: 42), no es una vía abierta para nosotros. Y esto no porque una empresa tal sea impracticable sino, especialmente, porque nuestros ojos ya no serían los mismos ante un resultado análogo.

3 Dado el recorte temporal, la referencia es principalmente a «Un mundo de palabra impresa entre Córdoba y Buenos Aires», capítulo de nuestra tesis doctoral en curso. No obstante, el mismo se inscribe en un proyecto colectivo de mayor pretensión, «Intelectuales, cultura impresa y mundo editorial. Córdoba en la geografía nacional e internacional de la cultura (1880-1980)», sostenido por el Programa Cultura escrita, mundo impreso, campo intelectual del Museo de Antropología de la UNC.

${ }^{4}$ Las características señaladas reenvían, en parte, a las adjudicadas por Foucault a la función-autor: su ligazón a un sistema jurídico institucional, su diversidad conforme a discursos y culturas, su artificialidad y, en menor medida para nuestro interés, su pluralidad de ego. Foucault (1985: 29).

${ }^{5}$ La importancia de las academias en la construcción de figuras intelectuales y autorales a escala nacional es innegable, aunque su incidencia sea desigual. En ocasiones, sus créditos llegan en el momento oportuno mientras que, en otras, tan tarde como para funcionar en verdad como lo que dicen ser, ámbitos de consagración. Entre ellas, la de Ciencias juega un papel singular en Córdoba, sede de su creación, siendo una temprana y «natural» vía de nacionalización de figuras locales.

${ }^{6}$ Esto es, no sólo sujetos de derecho privado o pública proscripción, ni meramente nombres propios, sino nombres asociados a una obra, resultado a la vez que estímulo de un público más o menos cuantioso.

7 Según ese programa y sus balances, la Nueva Revista buscaba llenar la «etapa intermediaria entre el diario y el libro», cosa que creía haber hecho, en primer término, respecto del Bosquejo de Garro, del cual había adelantado partes en sus tomos I y III. Suplemento a la entrega de marzo de 1882 de la Nueva Revista, Año I, T. II, marzo de 1882, pp. 8 y 9.

${ }^{8}$ El texto completo (540 páginas) fue editado en 1882 por Biedma, en Buenos Aires.

9 «Revista Bibliográfica» de Bosquejo Histórico de la Universidad de Córdoba, con un apéndice de documentos, por J. M. Garro, Nueva Revista de Buenos Aires, A. II, T. V, Agosto de 1882, p. 160.

${ }_{10}$ Activísimo en la contraofensiva antilaicista, Garro es Presidente de la Asociación Católica de Córdoba al momento de la Asamblea de Católicos Argentinos (1884); inmediatamente creada la Unión Nacional, asumirá junto a Jacinto Ríos la creación y dirección del diario El Porvenir, que se reconoce su órgano.

11 Puede sugerirse incluso una vinculación familiar entre Estrada y Biedma, en virtud del matrimonio de su hermano Ángel; refuerzan esta idea los continuos cruces de biedmas y estradas como autores o editores. Respecto de las objeciones efectuadas a Estrada por la estatización de ciertos hábitos familiar-comerciales, ver Eujanian (2000: 579).

12 Argañaras, Abraham, Rectificaciones críticas de la reciente Historia de la Universidad de Córdoba del Tucumán, s/d, Buenos Aires, 1883. La biblioteca particular de Cabrera constituyó desde 1936 la base de la del Instituto de Estudios Americanistas de la Universidad Nacional de Córdoba, y puede ser estudiada dentro de la actual Sección Americanistas de la Biblioteca de la Facultad de Filosofía y Humanidades; la del diplomático Juan Dussaut ha sido parcialmente caracterizada y relevada por Rolla Bertello (1991) en un trabajo que limita sus méritos a la transcripción de algunos títulos y pie de imprenta presentes en esa valiosa biblioteca privada.

13 Garro, Juan M., La Universidad de Córdoba bajo la dirección de los religiosos de San Francisco. Réplica al $R$. P. Fr. Abraham Argañaras, El Eco de Córdoba, Córdoba, 1884. Respecto de la «coyuntura católica» y el rol jugado en ella por Garro, puede verse la «Noticia Biográfica» que Manuel Río (hijo) hace de su padre, con marcada atención a su círculo, en Río (1967: 15-17).

${ }^{14}$ Entre 1891 y 1894 Garro tiene una importante presencia impresa a nivel local, autorizando la reproducción periodística de sus discursos políticos, y publicando algunos de ellos en forma de folleto. En lo que hace a su afirmación como figura cultural, participa en 1894 de la creación del Ateneo de Córdoba, asociación que integra entonces (y por varios años) como vicepresidente.

${ }^{15}$ Las Obras Completas de Estrada fueron editadas en 1896, en Buenos Aires, por la Librería del Colegio e impresas por la célebre Compañía Sudamericana de Billetes de Banco. Según Río (1967: 464), la «Noticia Biográfica» redactada por Garro fue objeto, además, de una edición especial de 60 ejemplares.

16 Los Escritos... también fueron impresos por la Compañía Sudamericana, así como la separata biográfica, de 47 páginas; el texto de Gez, originalmente impreso en Corrientes, sería luego reeditado varias veces en Buenos Aires por Weiss y Preusche. También en 1910, Garro fue designado por Sáenz Peña Ministro de Justicia, Culto e Instrucción Pública.

17 En 1915, había sido integrado a la Academia de Ciencias, reconocimiento tardío y de poca incidencia en su caso. Sorprende, sin embargo, su ausencia en la nómina de la Junta de Historia y Numismática, máxime cuando muchas de sus relaciones, de los Quesada al propio Gez, la integraban.

18 Cabrera, secular que llegaría a Monseñor, cultivó la historiografía colonial desde los noventa, siendo designado miembro correspondiente de la Junta de Historia en 1915. Director del archivo universitario, escribió asiduamente en la Revista de la Universidad (1914), con cuyo artífice, Enrique Martínez Paz, diseñó el plan de publicaciones de origen o tema colonial conocido como Biblioteca del Tercer Centenario (1915). Fue incorporado en 1915 como titular de la Academia Nacional de Ciencias, simultáneamente a Garro, Cárcano, Gil, Lugones y Figueroa Alcorta.

${ }^{19}$ Capdevila 1960: 7-8.

20 Al momento de esta edición, Gil era Ministro de Gobierno de Cárcano. En lo que hace a La Argentina, de Rossi, ésta congregó, entre otros, a Enrique Martínez Paz, Raúl Orgaz y Arturo Capdevila.

${ }^{21}$ El protagonismo de La Nación en la fábrica de autores y la creación de redes intelectuales a escala hispanoamericana ha sido puesto de relieve en el formidable trabajo de Julio Ramos (1989: 95-111).

22 También impreso por La Italia, de Biffignandi, como, estimamos, sus libros de 1903 y 1906.

${ }^{23}$ Fue Diputado Nacional entre 1926 y 1930, Director General de Meteorología e Inspector del Consejo Nacional de Educación luego de esa fecha.

${ }^{24}$ La de Deodoro es una mirada tempranamente corrosiva de un tipo de institución que gozaba de largo e indiscutido prestigio; indudablemente, el origen de la Academia de Letras, subproducto del golpe militar del treinta, la hacía también más apta para ello: «Uno de los sucesos más expresivos de la militarada de setiembre fue el florecimiento de cierto tipo de literatura -mala, naturalmente- y el auge de ciertos literatos que el turbión dictatorial puso en el centro de la correntada [...] ¿No es famosa la debilidad de los dictadores por la mala literatura? ¿No son ellos mismos, a veces, abominables literatos, desde Nerón a Leguía?». Roca (1935: 49). 